https://doi.org/10.15407/ujpe65.9.810

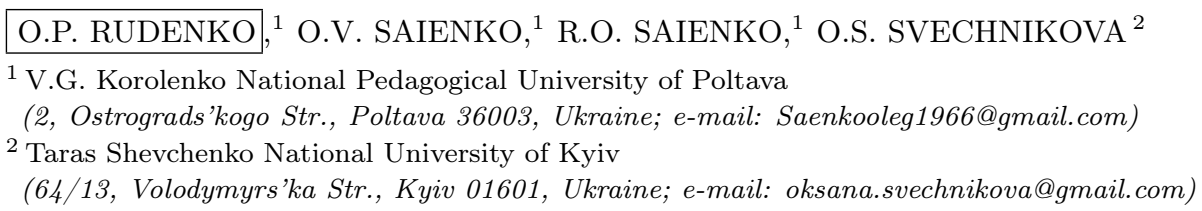

\title{
THERMODYNAMIC PARAMETERS OF THE VISCOUS FLOW IN THE AQUEOUS SOLUTIONS OF POLYOLS
}

\begin{abstract}
Data experimentally obtained for the kinematic viscosity are used to calculate the thermodynamic characteristics of viscous flows in some polyols and their aqueous solutions. The solutions of glycerol, erythritol, xylitol, adonite, sorbitol, mannitol, and dulcite are studied, as well as the melts of erythritol, xylitol, and sorbitol. The entropy, enthalpy, and free energy of the viscous flow are calculated in the framework of the theory of reaction rate constants. A linear dependence between the true entropy and the enthalpy of the viscous flow in the researched systems is found, which allowed us to determine the isokinetic temperature, calculate the transmission coefficient, draw a conclusion about the mechanisms of bond formation in the reaction centers of active complexes, and estimate the vibration energy of those bonds.
\end{abstract}

Ke ywords: viscosity, polyols, aqueous solutions, isokinetic temperature.

\section{Introduction}

Interest in studying the properties of sugar alcohols (polyhydric alcohols) and solutions on their basis is associated with a wide range of human activities, where those substances are applied; first of all, in food industry $[1,2]$ and medicine $[3,4]$. A large number of works dealt with the study of those properties that are crucial for those industries, in particular, the influence on the progress of various diseases $[3,4]$, changes in the taste of food, and transport parameters [1,2]. Much less attention, in our opinion, is paid to the study of the thermal motion of molecules in such objects and its thermodynamic characteristics [5-8]. In this work, we report the results of our studies concerning the thermodynamic parameters of a viscous flow, which were obtained on the basis of the data obtained for the shear viscosity coefficients of polyols, their aqueous solutions, and some of their melts.

Today, there are two approaches that can be used to calculate the thermodynamic parameters of a viscous flow. One of them is the so-called "activation" approach. It is used in the theories by Frenkel [9] and

(C) O.P. RUDENKO, O.V. SAIENKO, R.O. SAIENKO, O.S. SVECHNIKOVA, 2020
Eyring [10], as well as in the theory of reaction rate constants [11]. The other approach is called "non-activation" $[12,13]$. In this work, the activation approach was used to calculate the thermodynamic parameters of viscous flows in the aqueous solutions of some polyols that were studied experimentally.

\section{Research Methods and Objects}

The kinematic viscosity coefficient $\nu=\eta_{s} / \rho$ in the aqueous solutions of some polyols was measured in a temperature interval of $283-353 \mathrm{~K}$. The temperature was stabilized by an ultrathermostat with an error of $\pm 0.1^{\circ} \mathrm{C}$. The solutions were studied at a temperature of $293 \mathrm{~K}$ and in a wide range of concentrations: from diluted (with the concentration $C=1 \mathrm{wt} \%$ ) to almost saturated ones. The upper concentration limit for the solutions of each researched object was determined by the individual solubility of the specific polyol. For example, the studies were performed with the solutions of the following concentrations: glycerol $(10,20,40,50,70,80$, and $100 \mathrm{wt} \%)$, erythritol (1, $5,15,25,30$, and $35 \mathrm{wt} \%)$, xylitol $(5,10,20,30,40$, 50 , and $60 \mathrm{wt} \%)$, adonite $(10,20,30$, and 40 wt. $\%)$, sorbitol $(5,10,20,30.40,50,60$, and 70 wt. $\%)$, mannitol $(1,2,3,5,10,12$, and $15 \mathrm{wt} \%)$, and dulcite (1, 2 , and $3 \mathrm{wt} \%$ ).

ISSN 2071-0194. Ukr. J. Phys. 2020. Vol. 65, No. 9 
Polyhydric alcohols with a basic substance content of at least $99 \%$ and twice-distilled water were used to prepare the solutions. The solutions were prepared following the weight method. All required weighings were performed on an analytical balance with an error of $\pm 2 \times 10^{-4} \mathrm{~g}$. Before the solution preparation, the polyols were predried in a vacuum desiccator, with the temperature gradually increased to about $70{ }^{\circ} \mathrm{C}$.

Besides the aqueous solutions, the melts of erythritol, xylitol, and sorbitol were also studied. The latter were investigated within a temperature interval of $393-473 \mathrm{~K}$. The corresponding error of the temperature stabilization was $\pm 0.2{ }^{\circ} \mathrm{C}$.

The selected set of researched objects made it possible to trace the influence of such parameters as the carbon chain length and the number of $\mathrm{OH}$ - groups in the molecules (from 3 to 6 ), as well as the location of those groups, on the magnitude of the kinematic viscosity coefficient and the thermodynamic characteristics of the viscous flow. The latter is possible, because xylitol and adonite are pentahydric, whereas sorbitol, mannitol, and dulcite hexahydric alcohol isomers with the general formulas $\mathrm{C}_{5} \mathrm{O}_{5} \mathrm{H}_{12}$ and $\mathrm{C}_{6} \mathrm{O}_{6} \mathrm{H}_{14}$, respectively.

The shear viscosity of aqueous solutions was measured using a closed capillary viscometer with a hanging level, the design of which is described in patent [14]. The error of the shear viscosity measurements was $1-3 \%$.

\section{Experimental Results and Their Model Interpretation}

The experimental part of the work consisted in obtaining the temperature, $\nu=f(T)$, and concentration, $\nu=f(N)$, dependences of the kinematic viscosity coefficient for the researched objects. In the selected temperature interval from 283 to $353 \mathrm{~K}$, the temperature dependences for all studied solutions were similar both among themselves and to the temperature dependences of the kinematic viscosity in water and water-based liquid systems. As an example, the temperature dependences of the kinematic viscosity coefficient measured for the erythritol solutions are depicted in Fig. 1.

All concentration dependences of the kinematic viscosity coefficient demonstrate a monotonic growth with the polyol content in the solutions. This growth is especially rapid, if the solution temperature is

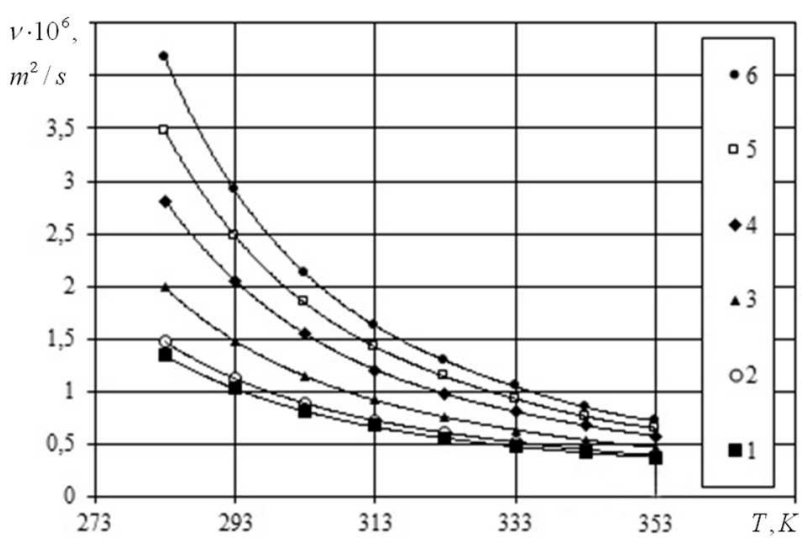

Fig. 1. Temperature dependences of the kinematic viscosity coefficient in the aqueous erythritol solutions with various concentrations: 1 (1), 5 (2), 15 (3), 25 (4), 30 (5), and $35 \mathrm{wt} \%$ (6)

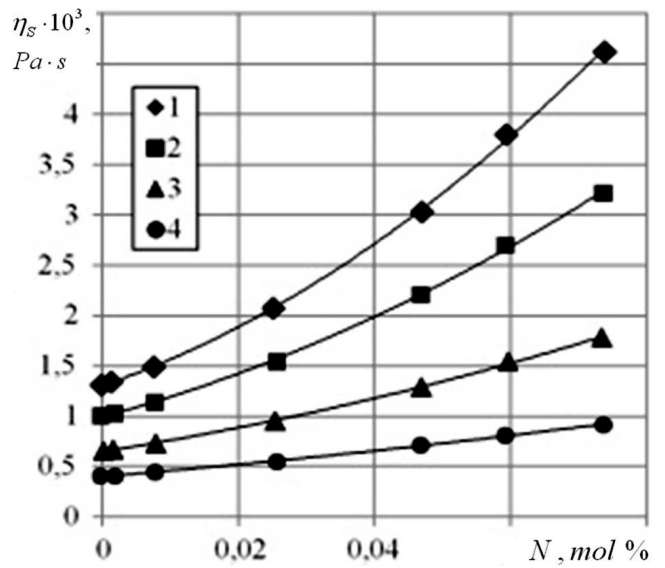

Fig. 2. Concentration dependences of the dynamic viscosity coefficient in the aqueous erythritol solutions at various temperatures: 283 (1), 293 (2), 313 (3), and $343 \mathrm{~K}$ (4)

"low". In Fig. 2, the concentration dependences of the kinematic viscosity coefficient for the erythritol solutions at temperatures of $283,293,313$, and $343 \mathrm{~K}$ are shown.

The application of the theory of reaction rate constants [11], which was used to describe shear deformations, implies that there are such processes in a liquid system which are conventionally classified as monomolecular reactions that break and form intermolecular bonds between associates and complexes in a dynamic system, e.g., the bulk of any liquid. In the framework of this model, it is also assumed that active complexes arise as a product of normal reactions. The latter are linear combinations of a number 
of elementary reactions giving rise to the break of intermolecular bonds between associates and complexes in the examined liquid systems [11].

The application of the theory of reaction rate constants when studying the viscous flow makes it possible to more deeply understand the physical nature of the kinetic compensation effect, as well as other relations. In particular, as was shown in work [11], in the framework of the theory of reaction rate constants, it is possible to obtain the Eyring equation by assuming that the liquid is "ideal". In the framework of the theory of reaction rate constants, it is also possible to determine the transmission coefficient and calculate the true changes in the entropy and free activation energy of a viscous flow.

The calculation procedure for the thermodynamic characteristics of a viscous flow in the framework of activation models is well known and described in the literature $[16,17]$. Its main stages are as follows.

1. On the basis of experimental data obtained for the kinematic viscosity coefficient $\nu$ and assuming the linear character of the dependence $\ln \nu=f\left(T^{-1}\right)$, the enthalpy $\Delta H_{\eta_{s}}^{\neq}$is calculated using the formula $[15,16]$

$\Delta H_{\eta_{s}}^{\neq}=R \frac{\partial \ln \nu}{\partial T^{-1}}$

2. The empirical free energy $\Delta G_{\eta_{s} e}^{\neq}$is calculated with the help of the formula [9]

$\Delta G_{\eta_{s} e}^{\neq}=R T \ln \frac{\nu \mu}{h N_{\mathrm{A}}}$,

where $R$ is the universal gas constant, $h$ Planck's constant, and $\mu$ the molar mass of the solution (substance). Expression (2) was obtained under the condition that the transmission coefficient is equal to unity (the values obtained under this assumption were called empirical [9]).

3. The empirical entropy $\Delta S_{\eta_{s}}^{\neq}$is determined from the equation

$\Delta G_{\eta_{s} e}^{\neq}=\Delta H_{\eta_{s}}^{\neq}-T \Delta S_{\eta_{s} e}^{\neq}$

4. By plotting the dependences $\Delta H_{\eta_{s}}^{\neq}=f\left(\Delta S_{\eta_{s}}^{\neq}\right)$, the presence (or absence) of the kinetic compensation effect $[15,16]$, i.e. the linear relation between the enthalpy and the empirical entropy of a viscous flow described by the equation

$\Delta H_{\eta_{s}}^{\neq}=A+T_{k}^{\neq} \Delta S_{\eta_{s} e}^{\neq}$, is established. Here, $T_{k}^{\neq}$is the isokinetic temperature of the active complex.

5. Provided that relation (4) is satisfied, the quantities $A$ and $T_{k}^{\neq}$in it can be determined, which allows the true parameters of the viscous flow activation to be calculated by the formulas

$\Delta G_{\eta_{s}}^{\neq}=\Delta G_{\eta_{s} e}^{\neq}+R T \ln (4 \pi e \propto)$,

$\Delta S_{\eta_{s}}^{\neq}=\Delta S_{\eta_{s} e}^{\neq}-R \ln (4 \pi e \propto)$,

where $\alpha$ is the transmission coefficient [11].

There are a few possible interpretations of the quantity $T_{k}^{\neq}$. For instance, this is a temperature at which the process changes abruptly [15]. Or this a temperature that determines the vibration frequency of those bonds in the reaction center of the active complex that will be broken [11]. Note also that if the temperature of the system is equal to the isokinetic temperature, $T=T_{k}^{\neq}$, the equation obtained for the kinematic viscosity in the framework of the Eyring theory coincides with its counterpart obtained from Newton's formula for viscous friction forces.

Attention has also to be focused on the fact that Eq. (4) is only a necessary but not a sufficient condition for establishing the presence of compensation effect. The sufficient condition consists in that the relation $\Delta G_{\eta_{s} e}^{\neq}=f(T)$ should be described by Eq. (3). Only the simultaneous satisfaction of Eqs. (3) and (4) testifies to the presence of the compensation effect.

The transmission coefficient $\propto$ in Eqs. (5) and (6) is the probability ratio between the appearance of a transition state in the active complex and all other possible ways of the active complex deactivation. This quantity determines a fluctuation in the vibrational energy of the active complex, $\Delta E^{+}$, that is necessary for the complex to transit into an unstable state followed by the break of intermolecular bonds,

$\Delta E^{+}=R T_{k}^{\neq} \sqrt{-\ln (2 \propto)}$.

In the framework of the analyzed model, the product $R T_{k}^{\neq}$is the standard fluctuation of the active complex energy. From Eq. (7), we can determine the number of phonons with the energy $R T_{k}^{\neq}$per mole that are required for the transition state of the active complex to appear [9].

ISSN 2071-0194. Ukr. J. Phys. 2020. Vol. 65, No. 9 


\section{Discussion of Results}

In Fig. 3, the dependences $\ln \nu=f\left(T^{-1}\right)$ for the erythritol aqueous solutions are depicted. For the aqueous solutions of other polyols, as well as for the studied melts, the corresponding dependences have the same linear behavior. Therefore, when calculating the thermodynamic parameters of a viscous flow, the model described above and Eqs. (2)-(4) were used.

Figure 4 demonstrates the dependences of the enthalpy on the empirical entropy for glycerol, erythritol, and xylitol. For other examined objects, the corresponding dependences are also linear within the determination error. In addition, the temperature dependences of the free energy correspond to Eq. (3). Hence, we may assert that the kinetic compensation effect is observed in the researched systems at the viscous flow in the studied temperature interval. This effect allows the isokinetic temperature $T_{k}^{\neq}$ to be determined from the slope of the dependence $\Delta H_{\eta_{s}}^{\neq}=f\left(\Delta S_{\eta_{s} e}^{\neq}\right)$according to Eq. (4). From the magnitude of the segment intercepted by this line on the abscissa axis, the transmission coefficient and the true entropy and free energy [Eqs. (5) and (6)] can be found.

The thermodynamic parameters of viscous flows, the isokinetic temperature, and the transmission coefficient calculated by formulas (1)-(6) for all researched systems are quoted in Table. First of all, attention is drawn to the negative values of the empirical entropy of the viscous flow activation in the xylitol and sorbitol solutions. Besides that, the temperature $T_{k}^{\neq}$in most of the considered systems varied within an interval of $600 \pm 90 \mathrm{~K}$. Only for the mannitol solutions, this temperature was $T_{k}^{\neq}=492 \mathrm{~K}$.

Such a behavior of the calculated quantities can be explained by the differences in the structure of the active complexes of the examined systems and the differences in intermolecular bonds associated with the molecular structure of each polyol, because we studied tri- to hexahydric alcohols, including their isomers. However, if the determination errors for the isokinetic temperature and the thermodynamic parameters of the viscous flow, which amounted to $15-20 \%$, are taken into account, such a behavior of $T_{k}^{\neq}$will indicate that the straight lines reflecting the enthalpy dependences on the empirical entropy will be parallel to one another, i.e. will have the same slope.

ISSN 2071-0194. Ukr. J. Phys. 2020. Vol. 65, No. 9

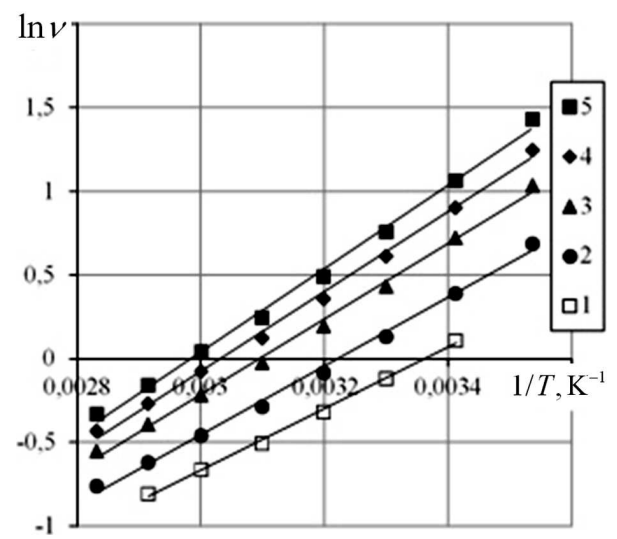

Fig. 3. Dependences of the logarithm of the kinematic viscosity coefficient on the inverse temperature for the erythritol aqueous solutions with various concentrations: 5 (1), 15 (2), 25 (3), 30 (4), and $35 \mathrm{wt} \%$ (5)

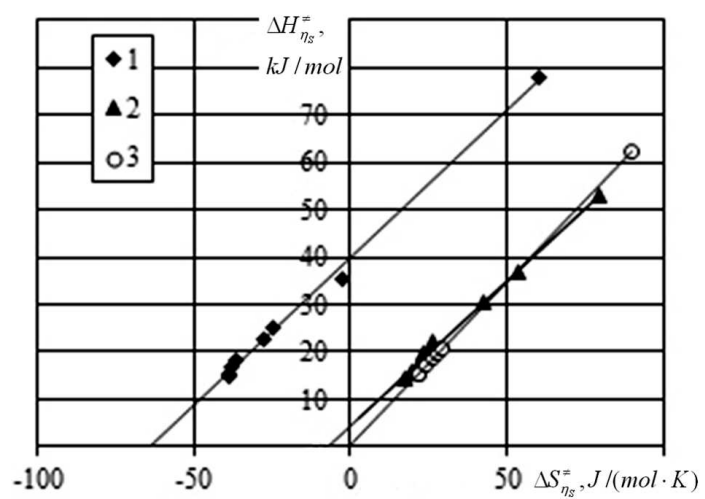

Fig. 4. Dependences of the enthalpy on the empirical entropy for the aqueous solutions of xylitol (1), glycerol (2), and erythritol (3)

Let us consider the enthalpy dependences on the true entropy that are shown in Fig. 5. From the presented data, one can see that the enthalpy and the true entropy of the viscous flow in the studied objects within their determination errors of $15-20 \%$ are accumulated along a straight line, the equation of which can be obtained using the least-squares method:

$\Delta H_{\eta_{s}}^{\neq=}=608 \Delta S_{\eta_{s}}^{\neq}$

When analyzing the research results, we assumed that the direction of this line coincides, within the determination errors for relevant quantities, with the direction of the linear dependence $\Delta H_{\eta_{s}}^{\neq}=f\left(\Delta S_{\eta_{s}}^{\neq}\right)$ obtained for melts and presented in Fig. 6. In Fig. 6, besides the values of thermodynamic parameters for 
Thermodynamic parameters of the viscous flow for the aqueous solutions and melts of polyols

\begin{tabular}{|c|c|c|c|c|c|c|c|c|}
\hline Compound & $C, \mathrm{wt} \%$ & $\Delta H_{\eta_{s}}^{\neq}, \mathrm{kJ} / \mathrm{mol}$ & $\Delta G_{\eta_{s} e}^{\neq}, \mathrm{kJ} / \mathrm{mol}$ & $\Delta S_{\eta_{s} e}^{\neq}, \mathrm{kJ} / \mathrm{mol}$ & $T_{k}^{\neq}, \mathrm{K}$ & $æ$ & $\Delta G_{\eta_{s}}^{\neq}, \mathrm{kJ} / \mathrm{mol}$ & $\Delta S_{\eta_{s}}^{\neq}, \mathrm{J} /(\mathrm{K} \mathrm{mol})$ \\
\hline \multirow[t]{7}{*}{ Glycerol } & 10 & 15.7 & 9.6 & 19.8 & \multirow[t]{7}{*}{606} & \multirow[t]{7}{*}{$1.1 \times 10^{-2}$} & 7.4 & 27.4 \\
\hline & 20 & 17.1 & 10.5 & 21.6 & & & 8.3 & 29.2 \\
\hline & 40 & 19.9 & 12.7 & 23.5 & & & 10.5 & 31.1 \\
\hline & 50 & 22.2 & 14.0 & 26.5 & & & 11.8 & 34.1 \\
\hline & 70 & 30.7 & 17.6 & 42.3 & & & 15.4 & 49.9 \\
\hline & 80 & 36.8 & 20.3 & 53.6 & & & 18.1 & 61.2 \\
\hline & 100 & 53.1 & 28.5 & 79.7 & & & 26.3 & 87.3 \\
\hline \multirow[t]{7}{*}{ Erythritol } & 1 & 15.2 & 8.9 & 21.6 & \multirow[t]{7}{*}{683} & \multirow[t]{7}{*}{$2.6 \times 10^{-2}$} & 8.7 & 22.5 \\
\hline & 5 & 15.5 & 9.2 & 21.7 & & & 9.0 & 22.6 \\
\hline & 15 & 17.1 & 10.0 & 24.1 & & & 9.8 & 25.0 \\
\hline & 25 & 18.8 & 11.0 & 26.4 & & & 10.8 & 27.3 \\
\hline & 30 & 19.8 & 11.6 & 28.1 & & & 11.2 & 29.0 \\
\hline & 35 & 20.7 & 12.1 & 29.5 & & & 11.9 & 30.3 \\
\hline & 100 & 62.1 & 25.8 & 90.0 & & & 26.4 & 90.9 \\
\hline \multirow[t]{8}{*}{ Xylitol } & 5 & 15.0 & 26.8 & -39.1 & \multirow[t]{8}{*}{620} & \multirow[t]{8}{*}{$1.3 \times 10^{-5}$} & 7.4 & 25.1 \\
\hline & 10 & 15.6 & 27.3 & -38.6 & & & 7.8 & 25.5 \\
\hline & 20 & 16.8 & 28.3 & -38.0 & & & 8.8 & 26.1 \\
\hline & 30 & 18.3 & 29.4 & -36.9 & & & 10.0 & 27.3 \\
\hline & 40 & 22.5 & 30.9 & -27.7 & & & 11.5 & 36.5 \\
\hline & 50 & 25.2 & 32.7 & -24.8 & & & 13.3 & 39.4 \\
\hline & 60 & 35.5 & 36.4 & -2.8 & & & 16.9 & 61.3 \\
\hline & 100 & 78.1 & 52.5 & 60.5 & & & 29.1 & 124.7 \\
\hline \multirow[t]{4}{*}{ Adonite } & 10 & 20.0 & 12.2 & 25.6 & \multirow[t]{4}{*}{570} & \multirow[t]{4}{*}{$9.5 \times 10^{-3}$} & 9.4 & 35.0 \\
\hline & 20 & 21.0 & 12.6 & 27.5 & & & 9.8 & 36.9 \\
\hline & 30 & 23.3 & 13.8 & 31.3 & & & 11.0 & 40.6 \\
\hline & 40 & 27.3 & 15.6 & 38.5 & & & 12.8 & 47.9 \\
\hline \multirow[t]{9}{*}{ Sorbitol } & 5 & 14.8 & 26.8 & -39.8 & \multirow[t]{9}{*}{601} & \multirow[t]{9}{*}{$1.6 \times 10^{-5}$} & 8.6 & 22.6 \\
\hline & 10 & 15.9 & 27.3 & -37.7 & & & 9.0 & 24.8 \\
\hline & 20 & 17.6 & 28.3 & -35.4 & & & 10.0 & 27.0 \\
\hline & 30 & 20.3 & 29.7 & -31.1 & & & 11.5 & 31.3 \\
\hline & 40 & 22.6 & 31.1 & -27.8 & & & 12.8 & 34.6 \\
\hline & 50 & 30.2 & 32.8 & -8.5 & & & 14.5 & 53.9 \\
\hline & 60 & 36.7 & 35.2 & 4.9 & & & 17.0 & 67.3 \\
\hline & 70 & 47.1 & 39.0 & 26.8 & & & 20.7 & 89.2 \\
\hline & 100 & 84.8 & 55.4 & 68.8 & & & 33.2 & 131.2 \\
\hline \multirow[t]{7}{*}{ Mannitol } & 1 & 14.2 & 9.1 & 16.6 & \multirow[t]{7}{*}{492} & \multirow[t]{7}{*}{$6.8 \times 10^{-3}$} & 5.4 & 28.8 \\
\hline & 2 & 14.3 & 9.2 & 16.8 & & & 5.5 & 29.0 \\
\hline & 3 & 14.4 & 9.3 & 16.8 & & & 5.6 & 29.0 \\
\hline & 5 & 15.4 & 9.7 & 19.5 & & & 5.5 & 31.7 \\
\hline & 10 & 16.3 & 9.8 & 21.2 & & & 6.1 & 33.4 \\
\hline & 12 & 16.6 & 10.2 & 21.6 & & & 6.2 & 33.7 \\
\hline & 15 & 17.3 & 11.6 & 22.6 & & & 6.5 & 34.8 \\
\hline \multirow[t]{3}{*}{ Dulcite } & 1 & 14.1 & 8.8 & 18.1 & \multirow[t]{3}{*}{624} & \multirow[t]{3}{*}{$1.7 \times 10^{-2}$} & 7.5 & 22.5 \\
\hline & 2 & 14.3 & 8.9 & 18.4 & & & 7.6 & 22.8 \\
\hline & 3 & 14.5 & 9.0 & 18.7 & & & 7.7 & 23.2 \\
\hline
\end{tabular}




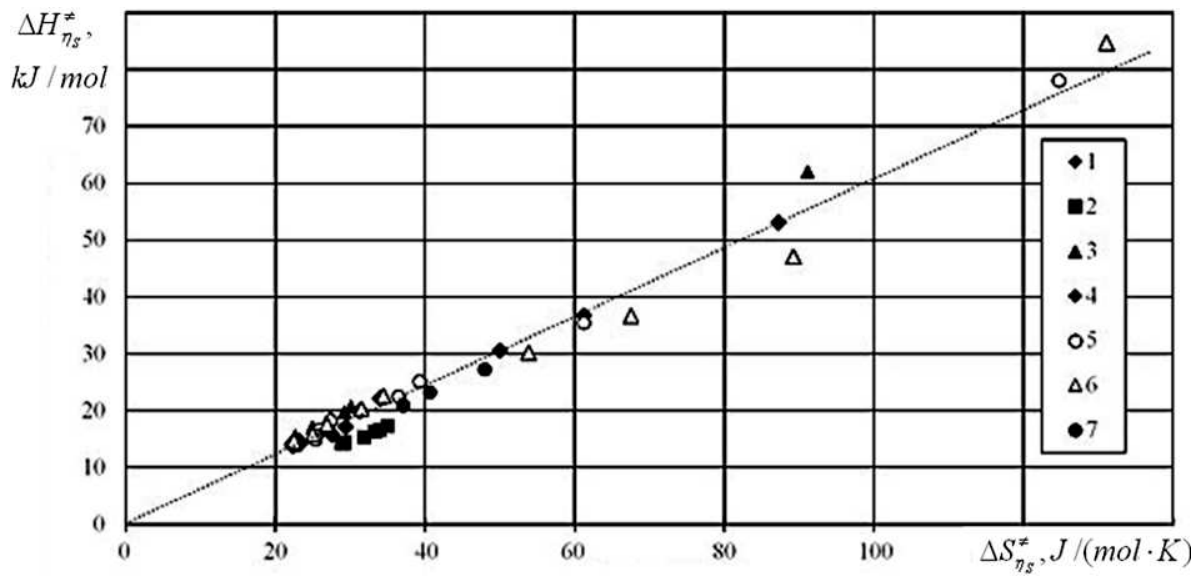

Fig. 5. Dependences of the enthalpy on the true entropy for the aqueous solutions of some polyols: dulcite (1), mannitol (2), erythritol (3), glycerol (4), xylitol (5), sorbitol (6), and adonite (7)

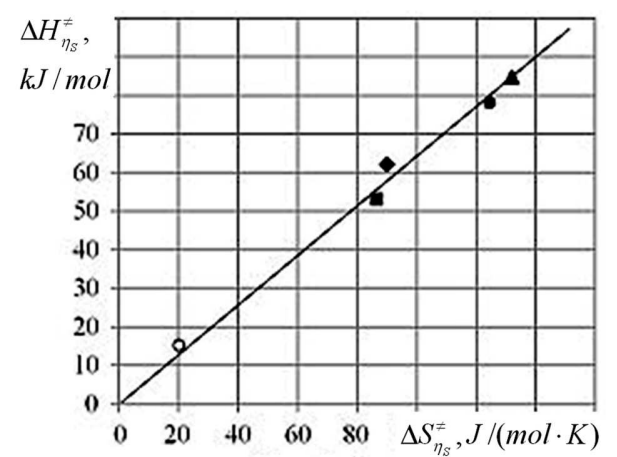

Fig. 6. The enthalpy versus true entropy diagram for the melts of glycerol (square), erythritol (diamond), xylitol (solid circle), sorbitol (triangle), and water (hollow circle)

the viscous flows in molten polyols, analogous values for water are also indicated. The thermodynamic characteristics of the viscous water flow were calculated by relations (1)-(3) within a temperature interval of $283 \pm 343 \mathrm{~K}$ according to the data of work [17]. From Fig. 6, we see that the dependence $\Delta H_{\eta_{s}}^{\neq}=f\left(\Delta S_{\eta_{s}}^{\neq}\right)$is linear, and the isokinetic temperature equals $641 \mathrm{~K}$. The latter value agrees with a value of $608 \mathrm{~K}$ within the error limits.

By analyzing the results obtained for the transmission coefficient values, some conclusions can be drawn about molecular reconstructions that accompany the processes of formation and disintegration of active complexes at the viscous flow. It is known that the process of active complex formation gives rise to a redistribution of bonds in the liquid without changing

ISSN 2071-0194. Ukr. J. Phys. 2020. Vol. 65, No. 9 their number. In this case, the value of the transmission coefficient $\propto$ has an order of $10^{-3}[11,16]$, and the composition of the active complex remains similar to the initial one. The break of weak chemical bonds of the $\mathrm{OH}$ type brings about the value $\propto \approx 10^{-4}$. In view of these data, we may assert that the processes of bond redistribution in the liquid without changing the bond number dominate during the viscous flow in such systems as the solutions of glycerol, erythritol, adonite, mannitol, and dulcite. At the same time, in the xylitol and sorbitol systems, the viscous flow is accompanied by the break of weak chemical bonds.

\section{Conclusions}

Our studies showed that the aqueous solutions of glycerol, erythritol, xylitol, adonite, sorbitol, mannitol, and dulcite, as well as the melts of glycerol, erythritol, xylitol, and sorbitol, demonstrate the kinetic compensation effect, i.e. a linear relation between the enthalpy and entropy of the viscous flow activation. In this case, within the determination errors, the corresponding dependences $\Delta H_{\eta_{s}}^{\neq}=f\left(\Delta S_{\eta_{s} e}^{\neq}\right)$are parallel to each other, which testifies to the equality of isokinetic temperatures in all studied systems. In our opinion, this behavior is associated with the fact that the vibration energies of those bonds in the reaction centers of active complexes that become broken during the viscous flow differ insignificantly among the examined systems or do not differ at all. At the same time, the processes of formation of active complexes and their compositions in those liquids are dif- 
ferent. For the majority of studied objects, the processes of active complex formation occur through the redistribution of bonds without changing their number, which favors the stability of a complex composition in the course of the viscous flow process. On the other hand, in the solutions of xylitol and sorbitol under the viscous flow condition, the formation of active complexes is accompanied by the break of weak chemical bonds, which results in a variation of the complex composition.

1. S. Ghosh, M.L. Sudha. A review on polyols: New frontiers for health-based bakery products. Int. J. Food Sci. Nut. 63, 372 (2012).

2. J.O. Metzger. Production of liquid hydrocarbons from biomass. Angew. Chem. Int. Ed. Engl. 45, 696 (2006).

3. N.I. Gumenyuk, V.Yu. Lishnevskaya. Influence of rheosorbilact on rheological blood properties in patients with coronary artery disease and chronic obstructive bronchitis. $U k r$. Pulmonol. Zh. N 3, 38 (2003) (in Russian).

4. V.L. Novak, I.V. Vovk, B.O. Kondrats'kyi, S.V. Prymak, M.P. Dzisiv, O.P. Novak, R.P. Dzis, L.G. Doroshenko, Ye.P. Karpovych, V.Ye. Chaban, I.M. Parobets'ka, V.V. Ivasyk. The effect of intravenous infusions of the new domestic "Rheosorbilact" medication on the blood urea value of patients following operations on the esophagus and stomach. Bukovyn. Med. Visn. 10, No. 2, 49 (2006) (in Ukrainian).

5. V. Pogorelov, L. Bulavin, I. Doroshenko, O. Fesjun, O. Veretennikov. The structure of liquid alcohols and the temperature dependence of vibrational bandwidth. J. Mol. Struct. 708, 61 (2004).

6. L. Bulavin, O. Belous, O. Svechnikova. Anomalous ultrasound attenuation near the critical point of n-pentanolnitromethane solution stratification. Ukr. J. Phys. 61, 375 (2019).

7. P. Golub, I. Doroshenko, V. Pogorelov. Quantum-chemical modeling of energy parameters and vibrational spectra of chain and cyclic clusters of monohydric alcohols. Phys. Lett. A 378, 1937 (2014).

8. V. Pogorelov, A. Yevglevsky, I. Doroshenko, L. Berezovchuk, Yu. Zhovtobryuch. Nanoscale molecular clusters and vibrational relaxation in simple alcohols. Superlatt. Microstruct. 44, 571 (2008).

9. J. Frenkel. Kinetic Theory of Liquids (Dover, 1955).
10. S. Gleston, K.J. Laider, H. Eyring. The Theory of Absolute Rate Processes (McGraw-Hill, 1941).

11. M.I. Shakhparonov. Mechanisms of Fast Processes in Liquids (Vysshaya Shkola, 1985) (in Russian).

12. N.P. Malomuzh, V.P. Oleynik. Nature of the kinematic shear viscosity of water. J. Struct. Chem. 49, 1055 (2008).

13. M.P. Malomuzh, O.P. Rudenko, A.M. Khlopov, L.M. Yagupol's'kyi. Peculiarities of the temperature dependence of kinematic shear viscosity of fluorine derivatives of benzene. Ukr. J. Phys. 55, 283 (2010).

14. R.O. Saienko, O.P. Rudenko, A.M. Getalo, O.V. Saienko, S.W. Stepanenko. Device for measuring the viscosity of liquid substanced. Patent of Ukraine No. 94735, MPK G01N 22, U201406993 (2014) (in Ukrainian).

15. L.A. Bulavin, A.M. Getalo, O.P. Rudenko, O.V. Khorolskyi. Influence of fluorination on the physical properties of normal aliphatic alcohols. Ukr. J. Phys. 60, 428 (2015).

16. V.I. Lebed, E.N. Glazkova. Physico-chemical properties of the system formic acid-water-1,4-dyoxan. Visn. Kharkiv. Nat. Univ. Ser. Khim. No. 669, 188 (2005) (in Russian).

17. I.T. Gronovskii, Yu.P. Nazarenko, E.F. Nekryach. Quick Reference on Chemistry (Naukova Dumka, 1974) (in Russian).

Received 13.04.20

Translated from Ukrainian by O.I. Voitenko

О.П. Руденко, О.В. Саєнко,

Р.О. Саєнко, О.С. Свечнікова

ТЕРМОДИНАМІЧНІ ХАРАКТЕРИСТИКИ

В'ЯЗКОЇ ТЕЧІЇ ВОДНИХ РОЗЧИНІВ РЯДУ ПОЛІОЛІВ

$\mathrm{P}$ е $з$ ю м е

У даній роботі експериментально одержані дані про кінематичну в'язкість використано для проведення розрахунків термодинамічних характеристик в'язкої течї деяких поліолів і водних розчинів на їх основі. Досліджувались розчини гліцерину, еритриту, ксиліту, адоніту, сорбіту, маніту, дульциту. Крім водних розчинів, були досліджені розплави еритриту, ксиліту і сорбіту. Розрахунок ентропії, ентальпї та вільної енергії в'язкої течії розчинів та розплавів проводився у рамках теорії констант швидкостей реакцій. Встановлена лінійна залежність між істинною ентропією і ентальпією в'язкої течії досліджуваних систем дозволила визначити ізокінетичну температуру, розрахувати трансмісійний коефіцієнт і зробити висновки про величину енергії коливань зв'язків реакційних центрів активних комплексів та способи їх утворення. 